\title{
Anesthetic management of hypertensive crisis in a three-year-old patient with undiagnosed severe renal artery stenosis
}

\section{-a case report-}

\author{
Sang-hee Park, Yoon-Sook Lee, Too Jae Min, Woon Young Kim, Jae Hwan Kim, and Young Cheol Park \\ Department of Anesthesiology and Pain Medicine, Korea University Ansan Hospital, Ansan, Korea
}

Pediatric hypertensive crisis is a potentially life threatening medical emergency, usually secondary to an underlying disease. Hypertension commonly occurs during general anesthesia, and is usually promptly and appropriately treated by anesthesiologists. However in children with severe, unexplained, or refractory hypertension, it has the potential to cause morbidity and even mortality in susceptible patients. We report an anesthetic management of an unexpected hypertensive crisis that developed during general anesthesia in a three-year-old girl with undiagnosed severe left renal artery stenosis. (Korean J Anesthesiol 2014; 67: 275-278)

Key Words: Anesthesia, Child, Renovascular hypertension.

Hypertensive crisis is defined as a sudden and abrupt elevation in blood pressure (BP). It is subclassified into hypertensive emergency and hypertensive urgency based on the presence or absence of end-organ damage [1]. Hypertensive crisis is rare in children, in whom secondary hypertension is predominant. Renal parenchymal disease, renal artery stenosis, coarctation of the aorta, and neuro-endocrine tumors need to be considered in its etiology [2]. Adult patients with hypertensive histories commonly develop severe hypertension while under general anesthesia, which can be successfully treated by anesthesiologists. However, in children with severe anesthesia-associated hypertension, management may be delayed and variable. The anesthetic management of a child with hypertensive crisis dur- ing general anesthesia has not been reported. We therefore present a rare case of hypertensive crisis that developed in a threeyear-old girl with undiagnosed renovascular hypertension due to left renal artery stenosis, who underwent general anesthesia for preauricular fistulectomy.

\section{Case Report}

A three-year-old girl was admitted to the hospital for right preauricular fistulectomy under general anesthesia. She was well-grown with a weight of $13 \mathrm{~kg}$ (25th percentile) and a height of $95.7 \mathrm{~cm}$ (50th percentile) and she had no medical history. Preoperative laboratory data including complete blood cell, co-

Received: June 5, 2013. Revised: 1st, July 5, 2013; 2nd, August 23, 2013. Accepted: September 23, 2013.

Corresponding author: Yoon-Sook Lee, M.D., Ph.D., Department of Anesthesiology and Pain Medicine, Korea University Ansan Hospital, 123, Jeokgeum-ro, Danwon-gu, Ansan 425-707, Korea. Tel: 82-31-412-5488, Fax: 82-31-412-5294, E-mail: yslee4719@gmail.com C) This is an open-access article distributed under the terms of the Creative Commons Attribution Non-Commercial License (http:// creativecommons.org/licenses/by-nc/3.0/), which permits unrestricted non-commercial use, distribution, and reproduction in any medium, provided the original work is properly cited. 
agulation test, and renal and liver function test were all within normal limits. Vital signs also were all unremarkable; heart rate (HR) was $114 / \mathrm{min}$ and regular, BP was $90 / 60 \mathrm{mmHg}$, and temperature was normal. Her peripheral pulses were normal and symmetrically palpable.

She was premedicated with midazolam $1 \mathrm{mg}$ and atropine 0.1 mg IM. On arrival in the operating room, electrocardiogram, pulse oxymetry, and non-invasive BP were established. HR was $154 / \mathrm{min}$ with normal sinus rhythm and $\mathrm{SpO}_{2}$ was $100 \%$. Anesthesia was induced with intravenous thiopental $5 \mathrm{mg} / \mathrm{kg}$ and rocuronium $0.6 \mathrm{mg} / \mathrm{kg}$. While she was manually ventilated with $2 \%$ sevoflurane and $100 \%$ oxygen via face mask, initial BP was measured 143/90 mmHg on the right arm. We administered fentanyl $10 \mu \mathrm{g}$ intravenously and intubated with a 4.5 $\mathrm{mm}$ ID cuffed endotracheal tube without difficulty. Anesthesia was maintained with $2 \%$ sevoflurane in $50 \%$ nitrous oxide and oxygen. $\mathrm{ETCO}_{2}$ was maintained 30 to $35 \mathrm{mmHg}$ and $\mathrm{SpO}_{2}$ was maintained $100 \%$. After intubation, BP increased as high as $180 / 100 \mathrm{mmHg}$ and HR was $160 / \mathrm{min}$. Because we suggested the cause of high BP was due to inadequate anesthetic depth, sevoflurane concentration was increased to $3 \%$ and intravenous fentanyl $10 \mu \mathrm{g}$ was injected two more times. HR was stabilized to $105 / \mathrm{min}$, but BP showed only slight decrease to averaging 140 $\mathrm{mmHg}$ of systolic blood pressure and was still high throughout the surgery. Immediately before extubation, BP increased up to 190/105 $\mathrm{mmHg}$ and HR was 98 /min. Intravenous nicardipine $0.1 \mathrm{mg}$ was given and she was sent to the recovery room. In the recovery room, BP increased to $220 / 115 \mathrm{mmHg}$. Intravenous fentanyl $10 \mu \mathrm{g}$ was given one more time, but BP did not decrease and was sometimes unmeasurable. She had no hypertensionrelated symptoms like headache or dizziness, but showed irrita-

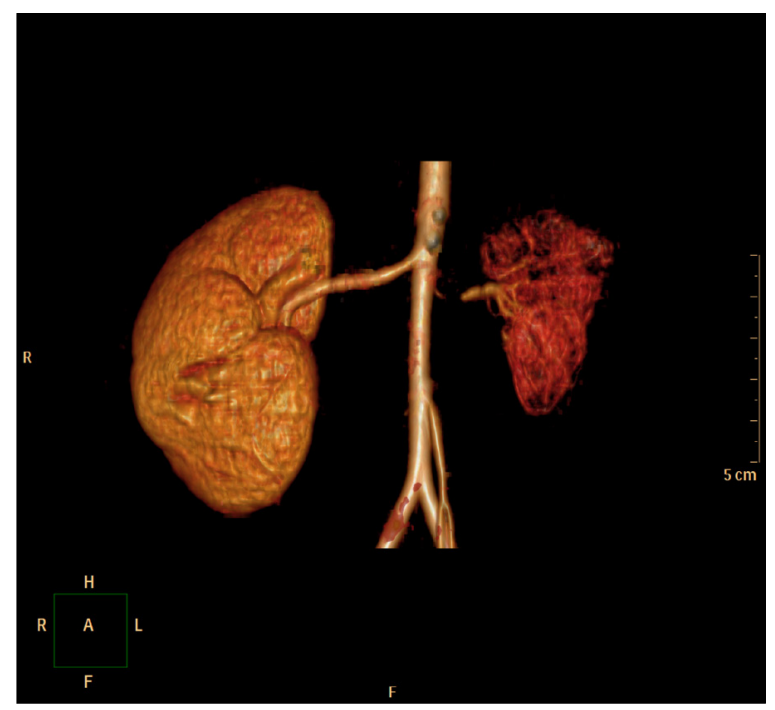

Fig. 1. Abdomen CT angiography shows stenosis at the proximal portion of left renal artery, hypoplasia, and decreased perfusion in left kidney. bility and agitation that weren't effectively controlled by opioids. We promptly consulted with the pediatrician and decided to transfer her to the pediatric department. Immediate antihypertensive treatment was started with nicardipine $0.5 \mu \mathrm{g} / \mathrm{kg} / \mathrm{min}$ in the recovery room.

In the pediatric ward, an additional labetalol $0.4-3 \mathrm{mg} / \mathrm{kg} / \mathrm{h}$ IV infusion was started, and diltiazem $3.5 \mathrm{mg} / \mathrm{kg} /$ day, atenolol $1 \mathrm{mg} / \mathrm{kg} /$ day, and hydralazine $7.2 \mathrm{mg} / \mathrm{kg} /$ day were given orally. Administration of these drugs was effective, but BP still showed fluctuation from $95 / 45$ to $145 / 75 \mathrm{mmHg}$. Concurrently, further evaluation to establish the cause of uncontrollable hypertension was performed. She had no past medical history and physical examinations were unremarkable. In laboratory findings, plasma renin activity was elevated up to $24.2 \mathrm{ng} / \mathrm{ml} / \mathrm{h}$ (normal range: $0.29-3.7 \mathrm{ng} / \mathrm{ml} / \mathrm{h}$ ). Plasma epinephrine and norepinephrine soared to $411.66 \mathrm{pg} / \mathrm{ml}$ (normal range: $0-120 \mathrm{pg} / \mathrm{ml}$ ) and $1,063.31 \mathrm{pg} / \mathrm{ml}$ (normal range: $0-410 \mathrm{pg} / \mathrm{ml}$ ) respectively. Other laboratory findings were all within normal limits. In imaging analyses, renal ultrasound showed a decrease in the size of the left kidney (5.7 cm in length) and no abnormalities were detected in the right kidney. Abdominal CT-angiography scan showed severe stenosis of inner diameter of less than $1 \mathrm{~mm}$ at proximal portion of left renal artery, hypoplasia, and decreased perfusion in left kidney (Fig. 1). Tc-99m DMSA renal scan also revealed decreased uptake in left kidney (Fig. 2). Echocardiography and fundoscopy were unremarkable. The options for treatment were balloon angioplasty or renal revascularization or nephrectomy. In this case, left nephrectomy was recommended due to the patient's age and the size of involved renal artery. Therefore, left laparoscopic nephrectomy was planned and she was transferred to the genitourinary department for surgery.

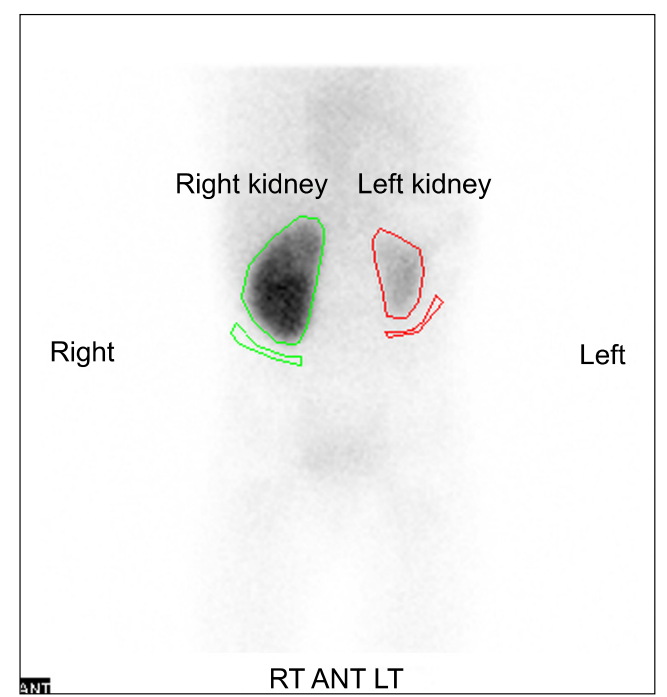

Fig. 2. Tc-99m DMSA renal scan shows decreased uptake in left kidney. 
Intravenous infusion of nicardipine $0.5 \mu \mathrm{g} / \mathrm{kg} / \mathrm{min}$ and labetalol $1 \mathrm{mg} / \mathrm{kg} / \mathrm{h}$ were continued until the day of surgery, BP measured in ward was stable at 100/41 $\mathrm{mmHg}$, and HR was $92 / \mathrm{min}$. Anesthesia was induced with thiopental and rocuronium. During the surgery, anesthesia was maintained with $6 \%$ desflurane in $50 \%$ nitrous oxide and oxygen. BP showed a mild elevation up to $130 / 85 \mathrm{mmHg}$ and intravenous infusion of nicardipine $0.5 \mu \mathrm{g} / \mathrm{kg} / \mathrm{min}$ and labetalol $1 \mathrm{mg} / \mathrm{kg} / \mathrm{h}$ were continued during induction and the early period of surgery. HR was maintained between 75 and $84 / \mathrm{min}$. Since BP was stabilized during the mid-period of surgery and HR fell to $68 / \mathrm{min}$, intravenous infusion was stopped. The 110 minute course of anesthesia was uneventful. BP was stable in the recovery room without medication and the child was sent to the ward with BP of $108 / 45 \mathrm{mmHg}$. There were no perioperative cardiovascular complications.

Although the drugs which were given preoperatively were continued, BP showed a certain fluctuation from 100/40 to 150/70 $\mathrm{mmHg}$ postoperatively. Enalapril $0.4 \mathrm{mg} / \mathrm{kg} /$ day was added orally with careful monitoring of renal function, and then BP was stabilized. After changing all intravenous drugs to oral medications (amlodipine, carvedilol and enalapril), BP remained stable. After 6 months of follow-up, the patient's BP was normalized with the aid of oral antihypertensive medications.

\section{Discussion}

We describe a three-year-old girl with hypertensive crisis that developed during induction of anesthesia and was exacerbated during emergence. Hypertensive crisis in early and mid-childhood is rare and is associated with significant morbidity and mortality. Hypertensive crisis in adults is defined as acute, severe elevation of blood pressure above 180/120 $\mathrm{mmHg}$ (about $20 \mathrm{mmHg}$ above stage 2 hypertension) [1]; however, hypertensive crisis in children has not been clearly defined. A child is diagnosed with hypertension if the average systolic and diastolic blood pressures are greater than the 95th percentile for age, gender, and height. Stage 1 hypertension is the designation for BP levels that range from 95th percentile to the 99th percentile plus $5 \mathrm{mmHg}$. Stage 2 hypertension is the designation for BP levels that are above the 99th percentile plus $5 \mathrm{mmHg}$ [3]. Our patient was three-yearold girl with a height of $95.7 \mathrm{~cm}$ (50th percentile), and stage 2 hypertension (average BP $>119 / 79 \mathrm{mmHg}$ ) [3]. Yang et al. [4] reported stage 2 hypertension may serve as a critical threshold for a high risk of hypertensive crisis in children.

Renovascular hypertension is caused by an arterial lesion that compromises blood flow in one or both kidneys, and represents $10 \%$ of all cases of secondary hypertension in children [5]. Renal artery stenosis is one of the most common abnormalities observed in children with secondary hypertension. The initial treatment of renovascular hypertension is medical therapy with antihypertensive drugs, the side effects of which can be exacerbated by rapid normalization of BP or drugs acting on the renin-angiotensin axis that reduce renal blood flow. Medications commonly used to treat hypertensive crisis in children are nicardipine, labetalol, and sodium nitroprusside. Our patient was given intravenous infusions of nicardipine and labetalol, as well as oral diltiazem, atenolol, and hydralazine. As medical treatment alone is often insufficient to control hypertension, leaving patients at risk for life-threatening events such as cerebrovascular accidents and cardiac failure, more aggressive treatments are required [6]. Management of hypertension can be quite challenging, especially in very young children and children with intra-renal artery involvement. Depending on the size of the vessels involved, endovascular or surgical intervention may not be possible. Nephrectomy may be indicated when the source of hypertension is a small, poorly functioning kidney [7].

The precipitating factors of hypertension during general anesthesia are most commonly related to drugs, excessive surgical stimulation, light anesthesia, or equipment [8]. If no obvious cause could be identified, it tends to be due to a combination of light anesthesia and/or excessive surgical stimulation and anesthesiologists often increase the depth of anesthesia. This will constitute effective treatment for the great majority of such cases. Once hypertension is identified and confirmed, its rapid control by the careful use of a volatile anesthetic agent, intravenous opioids, or rapid-acting antihypertensives will usually avoid serious morbidity [8]. If hypertension is unresponsive to the treatment indicated, an unusual etiology should be considered.

We did not measure baseline blood pressure before inducing anesthesia. Our patient presented with normal blood pressure and no signs and symptoms suggestive of hypertension preoperatively. She appeared anxious and irritable during the induction, despite having been premedicated with midazolam. In such cases of anxiety in young children, blood pressure measurement tends to be delayed until the patient loses consciousness. We had difficulty to recognize high BP after endotracheal intubation as hypertensive crisis because maintenance of high concentration of sevoflurane and administration of opioids decreased $\mathrm{BP}$ in some extent. However, BP soared to $220 / 115 \mathrm{mmHg}$ in the recovery room and she was postoperatively diagnosed as renovascular hypertension.

Our patient showed emergence agitation, unmeasurable blood pressure, and a hypertensive crisis with systolic blood pressure of more than $200 \mathrm{mmHg}$ in the postoperative period. Hypertensive crisis not only represents severely elevated blood pressure with end-organ dysfunction, also results from a complex cascade linking neuro-hormonal and hemodynamic pathways, causing blood pressure to spiral out of control. Renin-angiotensin-aldosterone activation, oxidative and mechanical damage to the microvasculature, fluid overload, severe renal dysfunction, sympathetic 
overstimulation, and endothelial dysfunction may all contribute to the pathology of hypertensive crisis $[9,10]$. The trigger factors in our patient are assumed to be sympathetic overstimulation due to endotracheal intubation, surgical stimuli, and postoperative pain, with her underlying compromised renal blood flow acting in synergy.

In conclusion, hypertensive crisis during the induction of anesthesia and postoperative period is rare in children, and anesthetic management can be difficult when there is no evident cause. Blood pressure measurement in perioperative period may be difficult due to uncooperative and restless infants and young children, but it is important nonetheless in diagnosing unexpected severe hypertension. We suggest that blood pressure should be monitored in infants and young children perioperatively, and that anesthesiologists should be aware of the management of the unexpected hypertensive crisis and the possibility of secondary hypertension in children.

\section{References}

1. Jones DW, Hall JE. Seventh report of the Joint National Committee on Prevention, Detection, Evaluation, and Treatment of High Blood Pressure and evidence from new hypertension trials. Hypertension 2004; 43: 1-3.

2. Chandar J, Zilleruelo G. Hypertensive crisis in children. Pediatr Nephrol 2012; 27: 741-51.

3. National high blood pressure education program working group on high blood pressure in children and adolescents. The fourth report on the diagnosis, evaluation, and treatment of high blood pressure in children and adolescents. Pediatrics 2004; 114(2 Suppl 4th Report): 555-76.

4. Yang WC, Zhao LL, Chen CY, Wu YK, Chang YJ, Wu HP. First-attack pediatric hypertensive crisis presenting to the pediatric emergency department. BMC Pediatr 2012; 12: 200.

5. Tullus K, Brennan E, Hamilton G, Lord R, McLaren CA, Marks SD, et al. Renovascular hypertension in children. Lancet 2008; 371 : 1453-63.

6. Stadermann MB, Montini G, Hamilton G, Roebuck DJ, McLaren CA, Dillon MJ, et al. Results of surgical treatment for renovascular hypertension in children: 30 year single centre experience. Nephro Dial Transplant 2010; 25: 807-13.

7. Meyers K, Falkner B. Hypertension in children and adolescents: an approach to management of complex hyper-tension in pediatric patients. Curr Hypertens Rep 2009; 11: 315-22.

8. Paix AD, Runciman WB, Horan BF, Chapman MJ, Currie M. Crisis management during anaesthesia: hypertension. Qual Saf Health Care 2005; 14: e12.

9. Flynn JT, Tullus K. Severe hypertension in children and adolescents: pathophysiology and treatment. Pediatr Nephrol 2009; 24: 1101-12.

10. Patel HP, Mitsnefes M. Advances in the pathogenesis and management of hypertensive crisis. Curr Opin Pediatr 2005; 17: 210-4. 